\title{
Functional Relationships between Lipid Metabolism and Liver Regeneration
}

\author{
David A. Rudnick ${ }^{1,2}$ and Nicholas O. Davidson ${ }^{2,3}$ \\ ${ }^{1}$ Department of Pediatrics, Washington University School of Medicine, P.O. Box 8208, St. Louis, MO 63110, USA \\ ${ }^{2}$ Department of Developmental Biology, Washington University School of Medicine, P.O. Box 8208, St. Louis, MO 63110, USA \\ ${ }^{3}$ Department of Medicine, Washington University School of Medicine, P.O. Box 8208, St. Louis, MO 63110, USA
}

Correspondence should be addressed to David A. Rudnick, rudnick_d@kids.wustl.edu

Received 13 June 2011; Revised 27 September 2011; Accepted 24 October 2011

Academic Editor: Karl G. Sylvester

Copyright ( 2012 D. A. Rudnick and N. O. Davidson. This is an open access article distributed under the Creative Commons Attribution License, which permits unrestricted use, distribution, and reproduction in any medium, provided the original work is properly cited.

The regenerative capacity of the liver is well known, and the mechanisms that regulate this process have been extensively studied using experimental model systems including surgical resection and hepatotoxin exposure. The response to primary mitogens has also been used to investigate the regulation of hepatocellular proliferation. Such analyses have identified many specific cytokines and growth factors, intracellular signaling events, and transcription factors that are regulated during and necessary for normal liver regeneration. Nevertheless, the nature and identities of the most proximal events that initiate hepatic regeneration as well as those distal signals that terminate this process remain unknown. Here, we review the data implicating acute alterations in lipid metabolism as important determinants of experimental liver regeneration and propose a novel metabolic model of regeneration based on these data. We also discuss the association between chronic hepatic steatosis and impaired regeneration in animal models and humans and consider important areas for future research.

\section{Introduction}

The liver has remarkable capacity to recover from injury. Such regenerative potential is essential for survival following partial hepatic resection (e.g., for tumor removal or livedonor liver transplantation) and from acute and chronic liver injury secondary to toxins, infections, immune dysfunction, metabolic diseases, or other causes [1-3]. Nevertheless, liver diseases remain an important cause of morbidity and mortality, and inadequate hepatic regeneration likely contributes. Based on these considerations, the mechanisms that regulate liver regeneration continue to be the subject of intense research, with hope that the knowledge gained will lead to novel strategies with which to improve the outcomes of many liver diseases. A number of studies have identified fatty liver as an important risk factor for impaired liver regeneration in humans and experimental animal models. In apparent distinction to those observations however, and still a lingering paradox in the literature, a number of reports suggest that the transient hepatocellular fat accumulation characteristic of early regeneration following partial hepatectomy $(\mathrm{PH})$ in rodents is actually required for physiological liver regeneration. Here, we review these data, propose a hypothesis for the seemingly dichotomous relationship of chronic versus acute hepatic fat accumulation on liver regeneration, and consider important areas for future research.

\section{Experimental Liver Regeneration}

The best characterized and most readily controlled experimental model for investigating the molecular, cellular, and physiologic mechanisms that control liver regeneration has been $\mathrm{PH}$ in rodents [4]. In the most typically used version of this paradigm, that is, "two-thirds" $\mathrm{PH}$, the anesthetized rodent is subjected to midventral laparotomy with sequential ligation and resection of the left and median hepatic lobes followed by closure of the surgical wounds and recovery. Subsequent regeneration is assessed by analyses of hepatocellular proliferation, liver mass, gene and protein expression, and signaling events at serial time points after the surgery. Studies using this experimental system show that regeneration after $\mathrm{PH}$ is precisely regulated in both 
its initiation and duration, terminating only when the original liver-to-body mass ratio is restored. Furthermore, this response does not require recruitment or mobilization of either a resident or exogenous stem cell population. Rather, all of the normally quiescent hepatocytes in the mature liver have the potential to proliferate in response to partial hepatic resection [5]. Pharmacological and genetic manipulations of animals subjected to $\mathrm{PH}$ have identified many signals, including cytokines (e.g., tumor necrosis factor $\alpha(\mathrm{TNF} \alpha)$ and interleukin 6 (IL6)), growth factors (e.g., hepatocyte growth factor (HGF), epidermal growth factorreceptor ligands, and fibroblast growth factors), intracellular signaling events (e.g., Wnt/ $\beta$-catenin), and transcription factors (e.g., NF $\kappa \mathrm{B}, \mathrm{STAT} 3, \mathrm{CREB}, \mathrm{C} / \mathrm{EBP} \beta, \mathrm{AP} 1, \mathrm{FXR}$, and LXR), that are regulated in response to $\mathrm{PH}$ and influence the subsequent hepatic regenerative response (reviewed in [1$3,5,6])$. Those signals, some of which are initiated within minutes of surgical resection, promote restoration of normal hepatic mass, architecture, and function over the ensuing days, after which regeneration ceases.

One advantage of the $\mathrm{PH}$ model of liver regeneration over others is the absence of injury to the remnant liver tissue following the (surgically induced) regenerative stimulus, which thereby minimizes potential confounders to interpretation of the functional specificity of induced signals for the regenerative response itself. Nevertheless, experimental models of toxin-induced liver regeneration (e.g., carbon tetrachloride $\left(\mathrm{CCl}_{4}\right)$, thioacetamide $\left.[7,8]\right)$ have also been extensively used to investigate regenerative mechanisms, and the importance of several regulatory pathways identified in the $\mathrm{PH}$ model has been shown to be conserved in such paradigms $[9,10]$. In contrast, the hepatocellular proliferative response to primary mitogens does not depend upon TNF $\alpha, \mathrm{HGF}, \mathrm{NF} \kappa \mathrm{B}$, and several other signals implicated as important in hepatic insufficiency-induced liver regeneration [11-16]. Despite the broad knowledge gained from almost a century of studies using these models, the nature and identities of the most proximal events that initiate hepatic regeneration as well as the distal events that terminate this process are still not known.

\section{The Metabolic Response to Hepatic Insufficiency and Liver Regeneration}

Liver mass is maintained or recovered in precise proportion to body mass, giving rise to the concept of an intrinsic regulator of liver: body mass ratio, that is, the "hepatostat" $[5,6]$. Amongst its many essential functions, the liver plays critical roles in the regulation of systemic metabolism and extrahepatic energy consumption, which themselves are influenced by body mass [17]. Together, these considerations suggest that changes in intermediary metabolism in response to hepatic insufficiency could contribute essential signals for initiation of liver regeneration, and, conversely, that restoration of metabolic homeostasis after recovery of the normal liver: body mass ratio might provide signals that terminate this response. Several experimental observations support such a metabolic model of liver regeneration.
3.1. Glucose Metabolism during Liver Regeneration. Consistent with the liver's central role in gluconeogenesis, rodents subjected to PH become hypoglycemic. Extending this paradigm, other studies show that either intravenous or enteral dextrose supplementation suppresses both $\mathrm{PH}-[18-$ $24]$ and toxin- $\left(\mathrm{CCl}_{4}\right.$, thioacetamide; $[25,26]$ and J. Huang and D.A. Rudnick, unpublished observations) -induced hepatocellular proliferation. Similarly, dietary caloric restriction accelerates onset of hepatocellular proliferation in response to surgical- or toxin-induced hepatic insufficiency $[27,28]$. Circulating insulin levels decline in response to $\mathrm{PH}$-induced hypoglycemia (and are augmented by dextrose supplementation [18]), and, interestingly, hepatocellular proliferation in models of toxin-induced liver injury is accelerated and augmented in mice with streptozotocin-induced insulindeficient diabetes $[29,30]$. Nevertheless, it remains to be established if changes in insulin signaling mediate the effects of dextrose supplementation on liver regeneration in such models. Somewhat paradoxically, studies have also shown that insulin supplementation reverses hepatic lobar atrophy in response to portacaval shunting in vivo and that insulin augments the activity of hepatocyte mitogens in cell culture [5]. This latter observation is consistent with studies, including those noted above, demonstrating that differences exist between the signals that regulate hepatocellular proliferation in response to surgical- or toxin-induced loss of liver mass and those that determine mitogen-induced proliferation.

Dextrose-mediated inhibition of $\mathrm{PH}$-induced liver regeneration is associated with disruption of many signaling events identified as important for regeneration. For example, provision of supplemental dextrose augments hepatic expression of the mitoinhibitory factors $\mathrm{C} / \mathrm{EBP} \alpha, \mathrm{p} 21$, and $\mathrm{p} 27$ and suppresses expression of the proregenerative transcriptional regulator, FoxM1, in animals subjected to $\mathrm{PH}$ [18]. Consistent with these findings, induction of proregenerative signals, including IL6, transforming growth factor $\alpha$ (TGF $\alpha$ ), and HGF, is accelerated by caloric restriction in toxin(thioacetamide)-induced liver regeneration [28]. Together, these observations support a model in which the hypoglycemic response to hepatic insufficiency initiates the signals that promote liver regeneration. Many of the regenerative signals that are disrupted by dextrose supplementation are also deranged in association with the impaired regenerative response observed in aged animals subjected to $\mathrm{PH}[31,32]$. Those changes in older mice appear to be mediated, at least in part, by age-dependent epigenetic effects [33, 34]. Together, these findings support a model in which the metabolic responses to hepatic insufficiency after PH (e.g., hypoglycemia) activate a transcriptional network through pathways including epigenetic regulation. In contrast to $\mathrm{PH}$-induced liver regeneration, toxin-induced regeneration is undiminished in old versus young animals [35]. The mechanisms responsible for this difference are unknown and merit further investigation.

3.2. Systemic Catabolism during Liver Regeneration. The observations noted above implicate hypoglycemia and subsequently induced alterations in systemic metabolism as 
modulators of physiological liver regeneration. This consideration has prompted further investigation of the metabolic response to hepatic insufficiency in experimental models of regeneration. Recent reports have characterized the stereotypical decline in systemic lean and adipose tissue stores and the ensuing rise in circulating and hepatic free fatty acids and specific amino acids that occur in response to $\mathrm{PH}$ prior to the onset of regeneration [36-38]. Those analyses also show that specific alterations in metabolism, like the regenerative response itself, occur in proportion to the extent of hepatic insufficiency [36]. For example, two-thirds PH results in a significantly greater loss of systemic adipose stores (and a more robust hepatocellular proliferative response) than does one-third hepatectomy [36]. Systemic fat depletion has also been observed in various models of toxin-induced liver regeneration $[36,39]$. These findings together suggest that catabolism of systemic adipose tissue might regulate the hepatic regenerative response to surgical and toxin-induced loss of liver mass.

3.3. Hepatic and Systemic Lipid Metabolism during Liver Regeneration. As noted above, it has long been recognized that the early regenerating liver transiently accumulates hepatocellular fat after PH [40-43]. Other work has demonstrated fat accumulation concomitant with cellular proliferation in primary hepatocyte culture [44], raising the possibility that fat accumulation might in turn regulate hepatocyte proliferation. Furthermore, the patterns of hepatic mRNA induction during early $\mathrm{PH}$-stimulated liver regeneration suggest the existence of a conserved transcriptional program leading to regulated transient "steatosis" during the regenerative response $[45,46]$. The role of endogenous hepatic lipogenesis in regulating liver regeneration is less clear. Increased de novo hepatic fatty acid production has been reported in regenerating liver [43], but mice with liver-specific disruption of fatty acid synthase expression (i.e., FASKOL mice, [47]) exhibit comparable hepatic fat accumulation (and liver regeneration) after $\mathrm{PH}$ compared to that in wild-type controls, strongly suggesting that de novo hepatic lipogenesis is not required for the development of such transient hepatic steatosis or the regenerative response [37]. These and other findings point to systemic adipose tissue as the primary source of the lipid that accumulates in regenerating liver $[39,40]$.

\section{Hepatic Steatosis during Experimental Liver Regeneration}

A number of experimental observations provide support for the possibility that the alterations in hepatic and systemic lipid metabolism discussed above are essential for normal liver regeneration. For example, older studies have noted increased dependency following $\mathrm{PH}$ of regenerating liver on $\beta$-oxidation of fatty acids for energy production [22, 48]. Indeed, it has been speculated that the inhibitory effect of dextrose supplementation on liver regeneration might be secondary to the suppressive effect of such supplementation on the release of free fatty acids from systemic adipose stores, and infusion of an inhibitor of $\beta$-oxidation, $((+)$-octanoylcarnitine), has been reported to impair regeneration [48]. Moreover, parenteral administration of lipid emulsions or of carnitine, which mediates uptake of acyl groups into mitochondria for $\beta$-oxidation, has been reported to accelerate $\mathrm{PH}$-induced regeneration [22], and dietary supplementation with palmitate and carnitine augments toxin- (thioacetamide)-induced hepatocellular proliferation [49]. However, questions about the role of alterations in $\beta$ oxidation have been raised by analyses of PPAR $\alpha$ knockout mice in which $\beta$-oxidation is dysregulated. Some reports demonstrate normal $\mathrm{PH}$-induced regeneration $[37,50]$, and others show impaired regeneration $[51,52]$ in these animals. More recent studies have reported inhibition of liver regeneration by various experimental interventions that decrease hepatic fat accumulation after partial hepatectomy, including both pharmacological (e.g., clofibrate [53], leptin [45], or propranolol [54] supplementation) and genetic (e.g., liverspecific disruption of glucocorticoid receptor expression, [45]) strategies. Those findings collectively imply a requisite role for hepatic steatosis in liver regeneration. However, as alluded to above, other findings raise questions about the specific function of hepatic fat accumulation during normal regeneration. For example, fat accumulation is suppressed but regeneration proceeds normally following $\mathrm{PH}$ in liver fatty acid binding protein (L-Fabp) knockout mice [37]. In addition, caveolin 1-null mice exhibit reduced hepatic steatosis after $\mathrm{PH}$, with regeneration reported to be impaired in one study [55] but not another [56]. Finally, regeneration proceeds normally in mice with intestine-specific deletion of the microsomal triglyceride transfer protein (MTP-IKO), which is essential for intestinal absorption of dietary fat and which exhibit decreased peripheral adipose tissue [37]. Importantly, hepatectomy-induced fat accumulation was reduced but not completely abrogated in L-Fabp-null and MTP-IKO mice [37], leading to speculation about the existence of a threshold of adaptive lipogenesis essential for regeneration but not influenced in those models. The role of mobilization of lipid from adipose tissue stores during $\mathrm{PH}-$ and toxin-induced liver regeneration has also been investigated by analyses of fatty liver dystrophy (fld) mice, which have a paucity of systemic adipose tissue as a result of global disruption of Lpin1 expression [57]. fld mice exhibit reduced hepatocellular triglyceride accumulation and proliferation with augmented hepatic p21 expression after $\mathrm{PH}$ compared to littermate controls [36]. fld mice also display increased mortality in response to $\mathrm{CCl}_{4}$-induced liver injury [36]. Taken together, these data support a model in which metabolism of systemic adipose tissue in response to hepatic insufficiency promotes initiation of hepatocellular proliferation. However, they do not establish the mechanisms responsible.

An important caveat to the analyses of fld mice is that the target gene of interest, Lpin1, is expressed in liver and muscle in addition to adipose tissue, and its expression is globally disrupted in fld mice [57]. Thus, Lpin1 might have effects on hepatic steatosis and hepatocellular proliferation during liver regeneration dependent on its hepatic expression and independent of its effects on systemic adipose tissue stores. Interestingly, hepatic Lpin1 expression is induced 
after $\mathrm{PH}$, and such induction is attenuated in liver-specific glucocorticoid receptor null mice, in which (as noted above) the metabolic and hepatocellular proliferative responses to $\mathrm{PH}$ are deranged ([45] and D. A. Rudnick, unpublished observations). These findings, together with the known pleiotropic functions of the protein product of Lpin1 (lipin1, [58]) suggest several potential alternative mechanisms to explain the impaired regenerative phenotype in fld mice [36]). For example, lipin 1 amplifies peroxisome proliferatoractivated receptor gamma coactivator $1 \alpha-(\mathrm{PGC} 1 \alpha-)$ regulated transcription in hepatocytes to increase expression of genes encoding enzymes involved in fatty acid oxidation (and known to be regulated during liver regeneration, $[59,60]$ ). Lipin1 also stimulates peroxisome proliferator-activated receptor $\gamma$ - (PPAR $\gamma$-) dependent adipogenic gene expression in adipocytes [61]. Finally, lipin 1 is a phosphatidic acid phosphatase enzyme, catalyzing the conversion of phosphatidic acid (PA) to diacylglycerol (DAG, [62]). This reaction plays a key role in triglyceride and phospholipid biosynthesis [63]. PA and DAG also function as lipid second messengers in protein kinase $C$ activation [64], which occurs during liver regeneration [65-67]. Thus, loss of the transcriptional or enzymatic activities of hepatic lipin 1 might contribute to impaired regeneration in fld mice.

A further consideration, not exclusive of those outlined above, is that alterations in hepatic and circulating pools of cholesterol might play a role in some phases of liver regeneration. This possibility has emerged from analyses in PCSK9 knockout mice, which exhibit decreased pools of circulating cholesterol, impaired regeneration, and hepatic necrosis after $\mathrm{PH}$, all of which are reversed by high cholesterol feeding [68]. Additional support for this idea comes from demonstration that ligand-induced liver X receptor (LXR) activation in mice subjected to $\mathrm{PH}$ alters plasma and hepatic cholesterol pools and impairs liver regeneration [69].

\section{A Metabolic Model of Liver Regeneration}

The data summarized above suggest that alterations in lipid metabolism that occur in response to hepatic insufficiency contribute to the initiation of both resection- and toxininduced liver regeneration. Although the specific mechanisms that couple changes in lipid metabolism to onset of hepatic regeneration have not been elucidated, several possibilities are worthy of consideration (Figure 1). For example, lipids delivered from the periphery or synthesized de novo in response to partial hepatic resection or other liver injury might serve simply as the substrate for energy production [70] or for membrane synthesis required for hepatocellular proliferation. Another intriguing consideration is that lipidderived metabolites might influence regenerative signaling pathways via transcriptional or epigenetic mechanisms. Several lines of evidence provide indirect support for this latter concept. For example, the transcriptional activities of the nuclear steroid hormone transcription factors $\operatorname{PPAR} \alpha, \mathrm{FXR}$, and LXR, which have each been implicated as important during $\mathrm{PH}$-induced liver regeneration $[51,52,69,71]$, are regulated by binding to specific classes of phospholipid [72], bile acids [71], or oxysterols [69], respectively. In addition, certain fatty acids have been reported to influence the acetylation state of metabolic enzymes in hepatocytes [73] and thus might also regulate epigenetic changes in regenerating liver. Finally, hepatic insufficiency-induced alterations in lipid metabolism might affect physiologic liver regeneration via adipose-derived hormones. Indeed, the influence of adipokines on regeneration has been suggested by studies showing inhibition of $\mathrm{PH}$-induced liver regeneration in wildtype mice by leptin supplementation [45] and impaired regeneration in adiponectin knockout mice $[74,75]$.

\section{Impaired Liver Regeneration in Experimental Models and Humans with Fatty Liver Disease}

The influence of adipose metabolism on liver regeneration has also been demonstrated by the recognized association between chronic hepatic steatosis and impaired regeneration in experimental animal models. Leptin-deficient $(o b / o b)$ [76-79] and -resistant $(d b / d b)$ [80, 81], diabetic KK-A(y) [82], "Western" [83] and high-fructose [84] diet-fed mice, and leptin-resistant obese Zucker rats [85, 86], each of which exhibit hepatic steatosis, have all been reported to demonstrate impeded regeneration after $\mathrm{PH}$ or $\mathrm{CCl}_{4}$ administration. In contrast, liver regeneration is not impaired in models of mild hepatic steatosis, including orotic acid[86] and choline- [87] deficient diet-fed rats, leading some investigators to speculate that the degree of steatosis is important in determining its effect on liver regeneration. Consistent with that interpretation, liver regeneration is variably affected in animals administered a methioninecholine deficient (MCD), a phenotype dependent on the magnitude of steatosis [86, 88-91]. Despite these many studies linking chronic hepatic steatosis with impaired liver regeneration, the mechanisms responsible remain enigmatic. Moreover, the basis for the differences in the influence of chronic and acute hepatic fat accumulation on regeneration is undefined.

Chronic steatosis has also been associated with adverse outcomes after major hepatic resection in humans. A recent meta-analysis showed that the risk of postoperative complications in patients with any degree of steatosis undergoing hepatectomy (for neoplasm) was double that of their nonsteatotic counterparts, and that those with excessive ( $>30 \%)$ steatosis had an almost 3-fold increased risk of death [92]. This analysis did not address whether impaired regeneration was the culprit; however, a study of patients undergoing liver resection (for living related liver donation) showed reduced recovery of liver volume over the initial 3 months following surgery in patients with mild steatosis (versus no steatosis, [93]), and another study reported decreased recovery of liver function 6-12 months after hepatectomy in such patients [94]. These findings are consistent with the animal model studies discussed above.

\section{Summary and Future Investigations}

As enumerated above, extensive older and more recent analyses implicate alterations in adipose metabolism in response to surgical- or toxin-induced hepatic insufficiency 


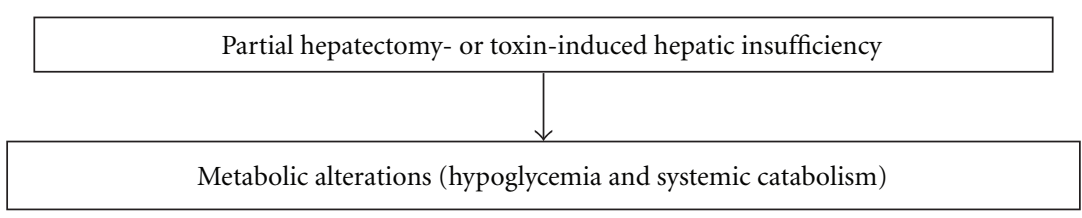

Experimental manipulations employed to alter the
metabolic response to PH:
Suppressed: supplementation with dextrose, leptin,
propranolol, clofibrate, Octanoylcarnitine; fld, liver GRKO
mice.
Augmented: caloric restriction; supplementation with lipid
emulsion, palmitate/carnitine; streptozotocin-induced diabetes.
None or variable: FASKOL, L-FABP KO, MTP-IKO, Caveolin1
KO, and PPAR $\alpha$ KO mice.
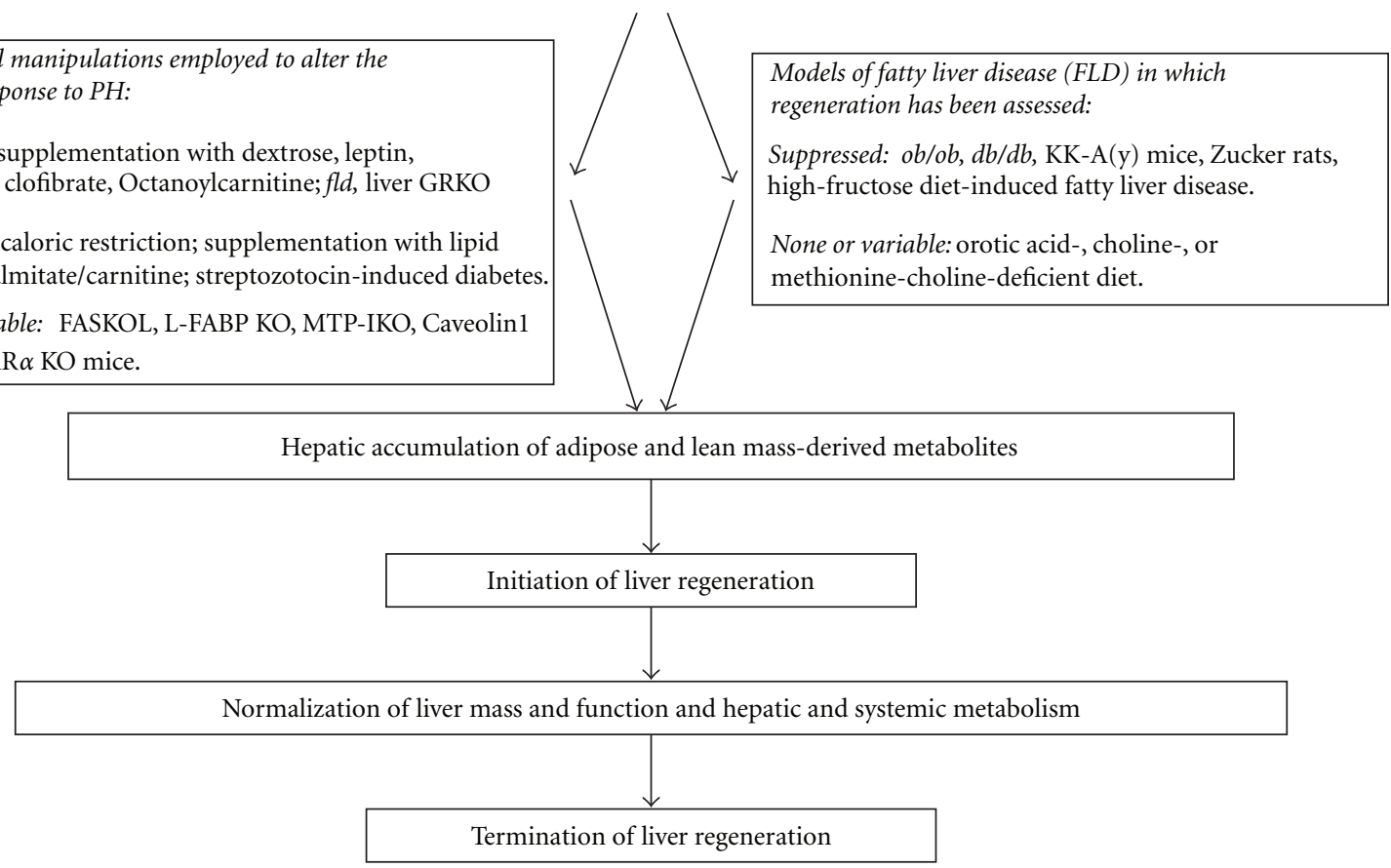

FIGURE 1: A metabolic model of liver regeneration: the data reviewed here implicate the metabolic response to hepatic insufficiency as a source of specific signals that initiate liver regeneration. Experimental manipulations employed to alter this metabolic response that are discussed in the text are listed in the box to the left (along with their reported effects on regeneration: suppressed, augmented, and none or variable effects). Models of fatty liver disease (FLD) in which regeneration has been assessed that are discussed in the text are listed in the box to the right. (fld: fatty liver dystrophy mouse; GRKO: glucocorticoid receptor knockout; FASKOL: liver-specific fatty acid synthase knockout mouse; L-Fabp KO: Liver fatty acid binding protein knockout; MTP-IKO: intestine-specific microsomal triglyceride transfer protein knockout; PPAR: peroxisome proliferator-activated receptor).

as functionally important for initiation of normal liver regeneration. However, the molecular basis for these effects has not yet been elucidated. Similarly, the mechanisms responsible for the inhibitory effect of chronic hepatic steatosis on liver regeneration in experimental model systems and humans undergoing hepatic resection remain to be established. It is tempting to speculate that the acute changes in systemic lipid metabolism that occur in response to hepatic insufficiency have specific, direct transcriptional, and epigenetic proregenerative effects, and that such events are modified or reversed in chronic fatty liver disease. Future studies should investigate the functional relationships between these metabolic, genetic, and epigenetic alterations during normal liver regeneration and examine the influence of chronic hepatic steatosis on those relationships.
FASKOL: Liver-specific fatty acid synthase knockout

GRKO: Glucocorticoid receptor knockout

HGF: Hepatocyte growth factor

IL6: $\quad$ Interleukin 6

L-Fabp KO: Liver fatty acid binding protein knockout

LXR: $\quad$ Liver $\mathrm{X}$ receptor

MTP-IKO: Intestine-specific microsomal triglyceride transfer protein knockout

PH: $\quad$ Partial hepatectomy

PA: $\quad$ Phosphatidic acid

PGC1 $\alpha$ : $\quad$ Peroxisome proliferator-activated receptor $\gamma$ coactivator $1 \alpha$

PPAR: $\quad$ Peroxisome proliferator-activated receptor

TGF: $\quad$ Transforming growth factor

TNF $\alpha$ : $\quad$ Tumor necrosis factor $\alpha$.

\section{Abbreviations}

$\mathrm{CCl}_{4}$ : Carbon tetrachloride

DAG: Diacyl glycerol

FLD: Fatty liver disease

fld: Fatty liver dystrophy mouse

\section{Acknowledgments}

Drs. D. A. Rudnick and N. O. Davidson are grateful to current and former members of their laboratories who contributed to the publications reviewed here. Studies from the 
authors' laboratories were supported by Grants DK-068219 (D. A. Rudnick), and HL-38180, DK-56260, and Digestive Disease Research Core Center DK-52574 (N. O. Davidson).

\section{References}

[1] G. K. Michalopoulos, "Liver regeneration," Journal of Cellular Physiology, vol. 213, no. 2, pp. 286-300, 2007.

[2] N. Fausto, "Liver regeneration," Journal of Hepatology, vol. 32, no. 1, pp. 19-31, 2000.

[3] R. M. Diehl and R. Rai, "Liver regeneration," in Schiff's Diseases of the Liver, R. Schiff, M. F. Sorrell, and W. C. Maddrey, Eds., pp. 39-54, Lippincott-Raven, Philadelphia, Pa, USA, 1999.

[4] G. M. Higgins and R. M. Anderson, "Experimental pathology of the liver. 1. Restoration of the liver of the white rat following partial surgical removal," Archives of Pathology, vol. 12, pp. 186-189, 1931.

[5] G. K. Michalopoulos and M. C. DeFrances, "Liver regeneration," Science, vol. 276, no. 5309, pp. 60-65, 1997.

[6] G. K. Michalopoulos, "Liver regeneration after partial hepatectomy: critical analysis of mechanistic dilemmas," American Journal of Pathology, vol. 176, no. 1, pp. 2-13, 2010.

[7] S. S. Anand and H. M. Mehendale, "Liver regeneration: a critical toxicodynamic response in predictive toxicology," Environmental Toxicology and Pharmacology, vol. 18, no. 2, pp. 149-160, 2004.

[8] H. M. Mehendale, "Tissue repair: an important determinant of final outcome of toxicant-induced injury," Toxicologic Pathology, vol. 33, no. 1, pp. 41-51, 2005.

[9] Y. Yamada and N. Fausto, "Deficient liver regeneration after carbon tetrachloride injury in mice lacking type 1 but not type 2 tumor necrosis factor receptor," American Journal of Pathology, vol. 152, no. 6, pp. 1577-1589, 1998.

[10] C. G. Huh, V. M. Factor, A. Sánchez, K. Uchida, E. A. Conner, and S. S. Thorgeirsson, "Hepatocyte growth factor/c-met signaling pathway is required for efficient liver regeneration and repair," Proceedings of the National Academy of Sciences of the United States of America, vol. 101, no. 13, pp. 4477-4482, 2004.

[11] A. Columbano and H. Shinozuka, "Liver regeneration versus direct hyperplasia," The FASEB Journal, vol. 10, no. 10, pp. 1118-1128, 1996.

[12] M. Menegazzi, A. Carcereri-De Prati, H. Suzuki et al., "Liver cell proliferation induced by nafenopin and cyproterone acetate is not associated with increases in activation of transcription factors NF- $\kappa \mathrm{B}$ and AP- 1 or with expression of tumor necrosis factor $\alpha$, Hepatology, vol. 25, no. 3, pp. 585$592,1997$.

[13] A. Columbano, G. M. Ledda-Columbano, M. Pibiri et al., "Increased expression of c-fos, c-jun and LRF-1 is not required for in vivo priming of hepatocytes by the mitogen TCPOBOP," Oncogene, vol. 14, no. 7, pp. 857-863, 1997.

[14] S. Skrtic, S. Ekberg, V. Wallenius, S. Enerbäck, L. Hedin, and J. O. Jansson, "Changes in expression of CCAAT/enhancer binding protein $\alpha(\mathrm{C} / \mathrm{EBP} \alpha)$ and $\mathrm{C} / \mathrm{EBP} \beta$ in rat liver after partial hepatectomy but not after treatment with cyproterone acetate," Journal of Hepatology, vol. 27, no. 5, pp. 903-911, 1997.

[15] A. Columbano and G. M. Ledda-Columbano, "Mitogenesis by ligands of nuclear receptors: an attractive model for the study of the molecular mechanisms implicated in liver growth," Cell Death and Differentiation, vol. 10, no. 1, pp. S19-S21, 2003.
[16] A. Columbano, G. M. Ledda-Columbano, M. Pibiri et al., "Gadd $45 \beta$ is induced through a CAR-dependent, TNFindependent pathway in murine liver hyperplasia," Hepatology, vol. 42, no. 5, pp. 1118-1126, 2005.

[17] J. P. Felber and A. Golay, "Regulation of nutrient metabolism and energy expenditure," Metabolism, vol. 44, no. 2, pp. 4-9, 1995.

[18] A. Weymann, E. Hartman, V. Gazit et al., "P21 is required for dextrose-mediated inhibition of mouse liver regeneration," Hepatology, vol. 50, no. 1, pp. 207-215, 2009.

[19] S. Bengmark, R. Olsson, and A. Svanborg, "The influence of glucose supply on liver steatosis and regeneration rate after partial hepatectomy," Acta Chirurgica Scandinavica, vol. 130, pp. 216-223, 1965.

[20] J. Simek, J. Mělka, M. Pospísil, and M. Neradilková, "Effect of protracted glucose infusion on the development of early biochemical changes and initiation of regeneration in rat liver after partial hepatectomy," Physiologia Bohemoslovenica, vol. 14, no. 4, pp. 366-370, 1965.

[21] J. A. Caruana, D. A. Whalen, and W. P. Anthony, "Paradoxical effects of glucose feeding on liver regeneration and survival after partial hepatectomy," Endocrine Research, vol. 12, no. 2, pp. 147-156, 1986.

[22] M. Holeček, "Nutritional modulation of liver regeneration by carbohydrates, lipids, and amino acids: a review," Nutrition, vol. 15, no. 10, pp. 784-788, 1999.

[23] J. Šimek, Vl. Chmelař, J. Mělka, J. Pazderka, and Z. Charvát, "Influence of protracted infusion of glucose and insulin on the composition and regeneration activity of liver after partial hepatectomy in rats," Nature, vol. 213, no. 5079, pp. 910-911, 1967.

[24] J. F. Ngala Kenda, B. De Hemptinne, and L. Lambotte, "Role of metabolic overload in the initiation of DNA synthesis following partial hepatectomy in the rat," European Surgical Research, vol. 16, no. 5, pp. 294-302, 1984.

[25] S. Chanda and H. M. Mehendale, "Nutritional impact on the final outcome of liver injury inflicted by model hepatotoxicants: effect of glucose loading," The FASEB Journal, vol. 9, no. 2, pp. 240-245, 1995.

[26] S. Chanda and M. Mehendale, "Role of nutrition in the survival after hepatotoxic injury," Toxicology, vol. 111, no. 1-3, pp. $163-178,1996$.

[27] A. G. Cuenca, W. Douglas Cress, R. A. Good, Y. Marikar, and R. W. Engelman, "Calorie restriction influences cell cycle protein expression and DNA synthesis during liver regeneration," Experimental Biology and Medicine, vol. 226, no. 11, pp. 1061-1067, 2001.

[28] U. M. Apte, P. B. Limaye, D. Desaiah, T. J. Bucci, A. Warbritton, and H. M. Mehendale, "Mechanisms of increased liver tissue repair and survival in diet-restricted rats treated with equitoxic doses of thioacetamide," Toxicological Sciences, vol. 72, no. 2, pp. 272-282, 2003.

[29] K. Shankar, V. S. Vaidya, T. Wang, T. J. Bucci, and H. M. Mehendale, "Streptozotocin-induced diabetic mice are resistant to lethal effects of thioacetamide hepatotoxicity," Toxicology and Applied Pharmacology, vol. 188, no. 2, pp. 122134, 2003.

[30] K. Shankar, V. S. Vaidya, U. M. Apte et al., "Type 1 diabetic mice are protected from acetaminophen hepatotoxicity," Toxicological Sciences, vol. 73, no. 2, pp. 220-234, 2003.

[31] N. A. Timchenko, M. Wilde, K. L. Kosai et al., "Regenerating livers of old rats contain high levels of $\mathrm{C} / \mathrm{EBP} \alpha$ that correlate with altered expression of cell cycle associated proteins," Nucleic Acids Research, vol. 26, no. 13, pp. 3293-3299, 1998. 
[32] N. A. Timchenko, "Old livers-C/EBPalpha meets new partners," Cell Cycle, vol. 2, no. 5, pp. 445-446, 2003.

[33] G. L. Wang, E. Salisbury, X. Shi, L. Timchenko, E. E. Medrano, and N. A. Timchenko, "HDAC1 promotes liver proliferation in young mice via interactions with $\mathrm{C} / \mathrm{EBP} \beta$," Journal of Biological Chemistry, vol. 283, no. 38, pp. 26179-26187, 2008.

[34] G. L. Wang, E. Salisbury, X. Shi, L. Timchenko, E. E. Medrano, and N. A. Timchenko, "HDAC1 cooperates with $\mathrm{C} / \mathrm{EBP} \alpha$ in the inhibition of liver proliferation in old mice," Journal of Biological Chemistry, vol. 283, no. 38, pp. 26169-26178, 2008.

[35] B. Murali, M. C. Korrapati, A. Warbritton, J. R. Latendresse, and H. M. Mehendale, "Tolerance of aged Fischer 344 rats against chlordecone-amplified carbon tetrachloride toxicity," Mechanisms of Ageing and Development, vol. 125, no. 6, pp. 421-435, 2004.

[36] V. Gazit, A. Weymann, E. Hartman et al., "Liver regeneration is impaired in lipodystrophic fatty liver dystrophy mice," Hepatology, vol. 52, no. 6, pp. 2109-2117, 2010.

[37] E. P. Newberry, S. M. Kennedy, Y. Xie et al., "Altered hepatic triglyceride content after partial hepatectomy without impaired liver regeneration in multiple murine genetic models," Hepatology, vol. 48, no. 4, pp. 1097-1105, 2008.

[38] D. A. Rudnick, D. J. Dietzen, Y. P. Turmelle et al., "Serum alpha-NH-butyric acid may predict spontaneous survival in pediatric acute liver failure," Pediatric Transplantation, vol. 13, no. 2, pp. 223-230, 2009.

[39] J. S. Klingensmith and H. M. Mehendale, "Chlordeconeinduced fat depletion in the male rat," Journal of Toxicology and Environmental Health, vol. 10, no. 1, pp. 121-129, 1982.

[40] E. A. Glende and W. S. Morgan, "Alteration in liver lipid and lipid fatty acid composition after partial hepatectomy in the rat," Experimental and Molecular Pathology, vol. 8, no. 2, pp. 190-200, 1968.

[41] T. J. Delahunty and D. Rubinstein, "Accumulation and release of triglycerides by rat liver following partial hepatectomy," Journal of Lipid Research, vol. 11, no. 6, pp. 536-543, 1970.

[42] A. Girard, P. S. Roheim, and H. A. Eder, "Lipoproten synthesis and fatty acid mobilization in rats after partial hepatectomy," Biochimica et Biophysica Acta, vol. 248, no. 1, pp. 105-113, 1971.

[43] C. D. Gove and D. A. Hems, "Fatty acid synthesis in the regenerating liver of the rat," Biochemical Journal, vol. 170, no. 1, pp. 1-8, 1978.

[44] G. Michalopoulos, H. D. Cianciulli, and A. R. Novotny, "Liver regeneration studies with rat hepatocytes in primary culture," Cancer Research, vol. 42, no. 11, pp. 4673-4682, 1982.

[45] E. Shteyer, Y. Liao, L. J. Muglia, P. W. Hruz, and D. A. Rudnick, "Disruption of hepatic adipogenesis is associated with impaired liver regeneration in mice," Hepatology, vol. 40, no. 6, pp. 1322-1332, 2004.

[46] S. Yu, K. Matsusue, P. Kashireddy et al., "Adipocyte-specific gene expression and adipogenic steatosis in the mouse liver due to peroxisome proliferator-activated receptor $\gamma 1$ $(\operatorname{PPAR} \gamma 1)$ overexpression," Journal of Biological Chemistry, vol. 278, no. 1, pp. 498-505, 2003.

[47] M. V. Chakravarthy, Z. Pan, Y. Zhu et al., “"New” hepatic fat activates PPAR $\alpha$ to maintain glucose, lipid, and cholesterol homeostasis," Cell Metabolism, vol. 1, no. 5, pp. 309-322, 2005.

[48] T. Nakatani, K. Ozawa, and M. Asano, "Differences in predominant energy substrate in relation to the resected hepatic mass in the phase immediately after hepatectomy," Journal of Laboratory and Clinical Medicine, vol. 97, no. 6, pp. 887-898, 1981.
[49] S. Chanda and H. M. Mehendale, "Role of nutritional fatty acid and L-carnitine in the final outcome of thioacetamide hepatotoxicity," The FASEB Journal, vol. 8, no. 13, pp. 10611068, 1994.

[50] M. S. Rao, J. M. Peters, F. J. Gonzalez, and J. K. Reddy, "Hepatic regeneration in peroxisome proliferator-activated receptor $\alpha$ null mice after partial hepatectomy," Hepatology Research, vol. 22, no. 1, pp. 52-57, 2002.

[51] M. D. Wheeler, O. M. Smutney, J. F. Check, I. Rusyn, R. Schulte-Hermann, and R. G. Thurman, "Impaired Ras membrane association and activation in $\operatorname{PPAR} \alpha$ knockout mice after partial hepatectomy," American Journal of Physiology, vol. 284, no. 2, pp. G302-G312, 2003.

[52] S. P. Anderson, L. Yoon, E. B. Richard, C. S. Dunn, R. C. Cattley, and J. C. Corton, "Delayed liver regeneration in peroxisome proliferator-activated receptor- $\alpha$-null mice," Hepatology, vol. 36, no. 3, pp. 544-554, 2002.

[53] S. R. Srinivasan, C. K. Chow, and H. P. Glauert, "Effect of the peroxisome proliferator ciprofibrate on hepatic DNA synthesis and hepatic composition following partial hepatectomy in rats," Toxicology, vol. 62, no. 3, pp. 321-332, 1990.

[54] J. Walldorf, C. Hillebrand, H. Aurich et al., "Propranolol impairs liver regeneration after partial hepatectomy in C57Bl/ 6-mice by transient attenuation of hepatic lipid accumulation and increased apoptosis," Scandinavian Journal of Gastroenterology, vol. 45, no. 4, pp. 468-476, 2010.

[55] M. A. Fernàndez, C. Albor, M. Ingelmo-Torres et al., "Caveolin-1 is essential for liver regeneration," Science, vol. 313, no. 5793, pp. 1628-1632, 2006.

[56] R. Mayoral, A. Fernández-Martínez, R. Roy, L. Boscá, and P. Martín-Sanz, "Dispensability and dynamics of caveolin1 during liver regeneration and in isolated hepatic cells," Hepatology, vol. 46, no. 3, pp. 813-822, 2007.

[57] M. Péterfy, J. Phan, P. Xu, and K. Reue, "Lipodystrophy in the fld mouse results from mutation of a new gene encoding a nuclear protein, lipin," Nature Genetics, vol. 27, no. 1, pp. 121124, 2001.

[58] K. Reue and P. Zhang, "The lipin protein family: dual roles in lipid biosynthesis and gene expression," FEBS Letters, vol. 582, no. 1, pp. 90-96, 2008.

[59] B. N. Finck, M. C. Gropler, Z. Chen et al., "Lipin 1 is an inducible amplifier of the hepatic PGC- $1 \alpha /$ PPAR $\alpha$ regulatory pathway," Cell Metabolism, vol. 4, no. 3, pp. 199-210, 2006.

[60] G. Asins, J. L. Rosa, D. Serra et al., "Gene expression of enzymes regulating ketogenesis and fatty acid metabolism in regenerating rat liver," Biochemical Journal, vol. 299, no. 1, pp. 65-69, 1994.

[61] Y. K. Koh, M. Y. Lee, J. W. Kim et al., "Lipin1 is a key factor for the maturation and maintenance of adipocytes in the regulatory network with CCAAT/enhancer-binding protein $\alpha$ and peroxisome proliferator-activated receptor $\gamma 2$," Journal of Biological Chemistry, vol. 283, no. 50, pp. 34896-34906, 2008.

[62] M. C. Gropler, T. E. Harris, A. M. Hall et al., "Lipin 2 is a liver-enriched phosphatidate phosphohydrolase enzyme that is dynamically regulated by fasting andobesity in mice," Journal of Biological Chemistry, vol. 284, no. 11, pp. 67636772, 2009.

[63] T. E. Harris, T. A. Huffman, A. Chi et al., "Insulin controls subcellular localization and multisite phosphorylation of the phosphatidic acid phosphatase, lipin 1," Journal of Biological Chemistry, vol. 282, no. 1, pp. 277-286, 2007.

[64] D. Lang, J. N. Kanfer, G. Goracci, and L. Freysz, "Production and function of lipid second messengers in proliferating and 
differentiated neuroblastoma cells," Journal of Lipid Mediators and Cell Signalling, vol. 14, no. 1-3, pp. 349-359, 1996.

[65] Y. Okamoto, K. Nishimura, M. Nakayama, M. Nakagawa, and H. Nakano, "Protein kinase C in the regenerating rat liver," Biochemical and Biophysical Research Communications, vol. 151, no. 3, pp. 1144-1149, 1988.

[66] M. Houweling, W. J. Vaartjes, and L. M. G. Van Golde, "Isozymic forms of protein kinase C in regenerating rat liver," FEBS Letters, vol. 247, no. 2, pp. 487-491, 1989.

[67] J. A. Daller, A. R. Buckley, F. W. Van Hook, D. J. Buckley, and C. W. Putnam, "Suramin, a protein kinase C inhibitor, impairs hepatic regeneration," Cell Growth and Differentiation, vol. 5, no. 7, pp. 761-767, 1994.

[68] A. Zaid, A. Roubtsova, R. Essalmani et al., "Proprotein convertase subtilisin/kexin type 9 (PCSK9): hepatocyte-specific lowdensity lipoprotein receptor degradation and critical role in mouse liver regeneration," Hepatology, vol. 48, no. 2, pp. 646654, 2008.

[69] S. G. Lo, N. Celli, M. Caboni et al., "Down-regulation of the lxr transcriptome provides the requisite cholesterol levels to proliferating hepatocytes," Hepatology, vol. 51, no. 4, pp. 1334-1344, 2010.

[70] G. C. Farrell, "Probing prometheus: fat fueling the fire?" Hepatology, vol. 40, no. 6, pp. 1252-1255, 2004.

[71] W. Huang, K. Ma, J. Zhang et al., "Nuclear receptor-dependent bile acid signaling is required for normal liver regeneration," Science, vol. 312, no. 5771, pp. 233-236, 2006.

[72] M. V. Chakravarthy, I. J. Lodhi, L. Yin et al., "Identification of a physiologically relevant endogenous ligand for PPAR $\alpha$ in liver," Cell, vol. 138, no. 3, pp. 476-488, 2009.

[73] S. Zhao, W. Xu, W. Jiang et al., "Regulation of cellular metabolism by protein lysine acetylation,” Science, vol. 327, no. 5968, pp. 1000-1004, 2010.

[74] R. Z. Shu, F. Zhang, F. Wang et al., "Adiponectin deficiency impairs liver regeneration through attenuating STAT3 phosphorylation in mice," Laboratory Investigation, vol. 89, no. 9, pp. 1043-1052, 2009.

[75] H. Ezaki, Y. Yoshida, Y. Saji et al., "Delayed liver regeneration after partial hepatectomy in adiponectin knockout mice," Biochemical and Biophysical Research Communications, vol. 378, no. 1, pp. 68-72, 2009.

[76] S. Q. Yang, A. K. Mandal, J. Huang, and A. M. Diehl, "Disrupted signaling and inhibited regeneration in obese mice with fatty livers: implications for nonalcoholic fatty liver disease pathophysiology," Hepatology, vol. 34, no. 4 I, pp. 694706, 2001.

[77] M. Torbenson, S. Q. Yang, H. Z. Liu, J. Huang, W. Gage, and A. M. Diehl, "Stat-3 overexpression and p21 up-regulation accompany impaired regeneration of fatty livers," American Journal of Pathology, vol. 161, no. 1, pp. 155-161, 2002.

[78] I. A. Leclercq, M. Vansteenberghe, V. B. Lebrun et al., "Defective hepatic regeneration after partial hepatectomy in leptin-deficient mice is not rescued by exogenous leptin," Laboratory Investigation, vol. 86, no. 11, pp. 1161-1171, 2006.

[79] I. A. Leclercq, J. Field, and G. C. Farrell, "Leptin-specific mechanisms for impaired liver regeneration in ob/ob mice after toxic injury," Gastroenterology, vol. 124, no. 5, pp. 14511464, 2003.

[80] H. Yamauchi, K. Uetsuka, T. Okada, H. Nakayama, and K. Doi, "Impaired liver regeneration after partial hepatectomy in db/db mice," Experimental and Toxicologic Pathology, vol. 54, no. 4, pp. 281-286, 2003.
[81] M. Shirai, H. Yamauchi, H. Nakayama, K. Doi, and K. Uetsuka, "Expression of epidermal growth factor receptor protein in the liver of $\mathrm{db} / \mathrm{db}$ mice after partial hepatectomy," Experimental and Toxicologic Pathology, vol. 59, no. 3-4, pp. 157-162, 2007.

[82] T. Aoyama, K. Ikejima, K. Kon, K. Okumura, K. Arai, and S. Watanabe, "Pioglitazone promotes survival and prevents hepatic regeneration failure after partial hepatectomy in obese and diabetic KK-Ay mice," Hepatology, vol. 49, no. 5, pp. 16361644, 2009.

[83] R. A. DeAngelis, M. M. Markiewski, R. Taub, and J. D. Lambris, "A high-fat diet impairs liver regeneration in C57BL/6 mice through overexpression of the NF- $\kappa \mathrm{B}$ inhibitor, $\mathrm{I} \kappa \mathrm{B} \alpha$," Hepatology, vol. 42, no. 5, pp. 1148-1157, 2005.

[84] S. Tanoue, H. Uto, R. Kumamoto et al., "Liver regeneration after partial hepatectomy in rat is more impaired in a steatotic liver induced by dietary fructose compared to dietary fat," Biochemical and Biophysical Research Communications, vol. 407, no. 1, pp. 163-168, 2011.

[85] M. Selzner and P. A. Clavien, "Failure of regeneration of the steatotic rat liver: disruption at two different levels in the regeneration pathway," Hepatology, vol. 31, no. 1, pp. 35-42, 2000.

[86] C. Picard, L. Lambotte, P. Starkel et al., "Steatosis is not sufficient to cause an impaired regenerative response after partial hepatectomy in rats," Journal of Hepatology, vol. 36, no. 5, pp. 645-652, 2002.

[87] M. S. Rao, K. Papreddy, M. Abecassis, and T. Hashimoto, "Regeneration of liver with marked fatty change following partial hepatectomy in rats," Digestive Diseases and Sciences, vol. 46, no. 9, pp. 1821-1826, 2001.

[88] B. H. Zhang, M. Weltman, and G. C. Farrell, "Does steatohepatitis impair liver regeneration? A study in a dietary model of non-alcoholic steatohepatitis in rats," Journal of Gastroenterology and Hepatology, vol. 14, no. 2, pp. 133-137, 1999.

[89] R. Veteläinen, R. J. Bennink, A. K. Van Vliet, and T. M. Van Gulik, "Mild steatosis impairs functional recovery after liver resection in an experimental model," British Journal of Surgery, vol. 94, no. 8, pp. 1002-1008, 2007.

[90] R. Veteläinen, A. K. Van Vliet, and T. M. Van Gulik, "Severe steatosis increases hepatocellular injury and impairs liver regeneration in a rat model of partial hepatectomy," Annals of Surgery, vol. 245, no. 1, pp. 44-50, 2007.

[91] S. Donthamsetty, V. S. Bhave, M. S. Mitra, J. R. Latendresse, and H. M. Mehendale, "Nonalcoholic fatty liver sensitizes rats to carbon tetrachloride hepatotoxicity," Hepatology, vol. 45, no. 2, pp. 391-403, 2007.

[92] V. E. De Meijer, B. T. Kalish, M. Puder, and J. N. M. IJzermans, "Systematic review and meta-analysis of steatosis as a risk factor in major hepatic resection," British Journal of Surgery, vol. 97, no. 9, pp. 1331-1339, 2010.

[93] J. Y. Cho, K. S. Suh, C. H. Kwon, N. J. Yi, and K. U. Lee, "Mild hepatic steatosis is not a major risk factor for hepatectomy and regenerative power is not impaired," Surgery, vol. 139, no. 4, pp. 508-515, 2006.

[94] M. Kaibori, S. K. Ha-Kawa, Y. Uchida et al., "Liver regeneration in donors evaluated by Tc-99m-GSA scintigraphy after living donor liver transplantation," Digestive Diseases and Sciences, vol. 53, no. 3, pp. 850-855, 2008. 


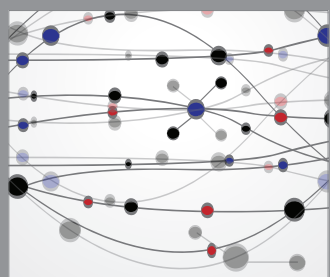

The Scientific World Journal
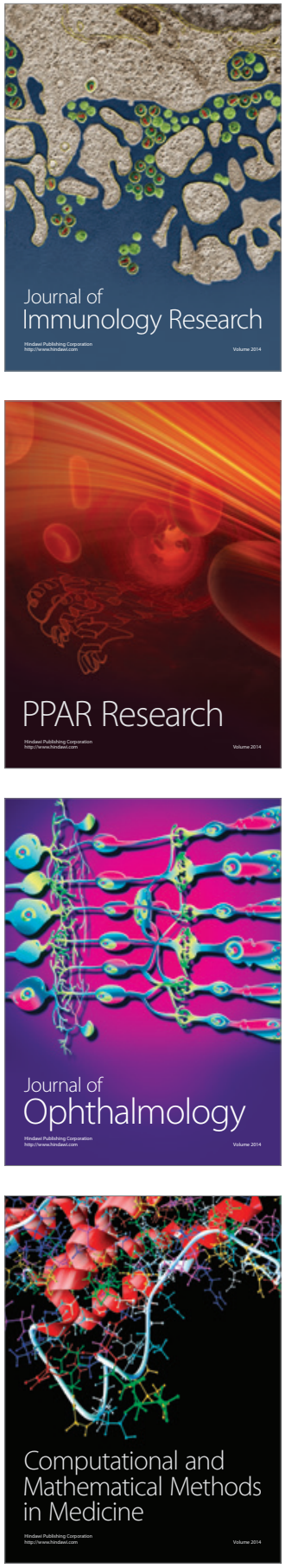

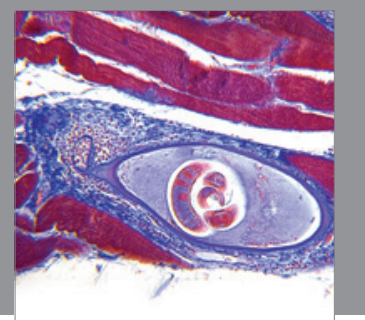

Gastroenterology

Research and Practice
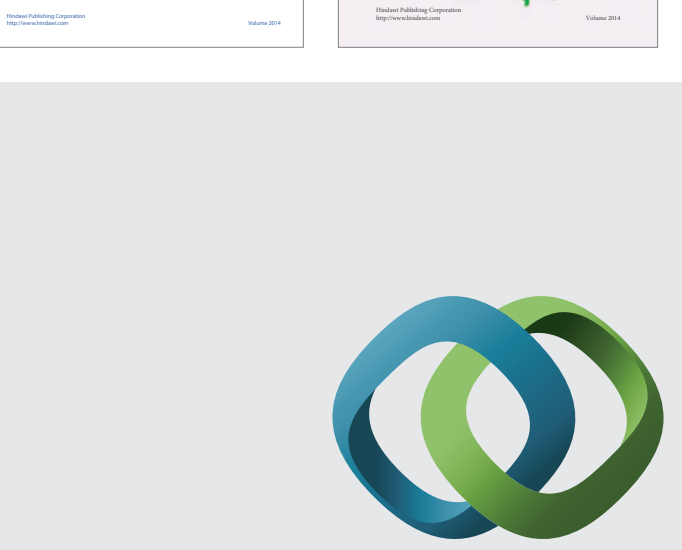

\section{Hindawi}

Submit your manuscripts at

http://www.hindawi.com
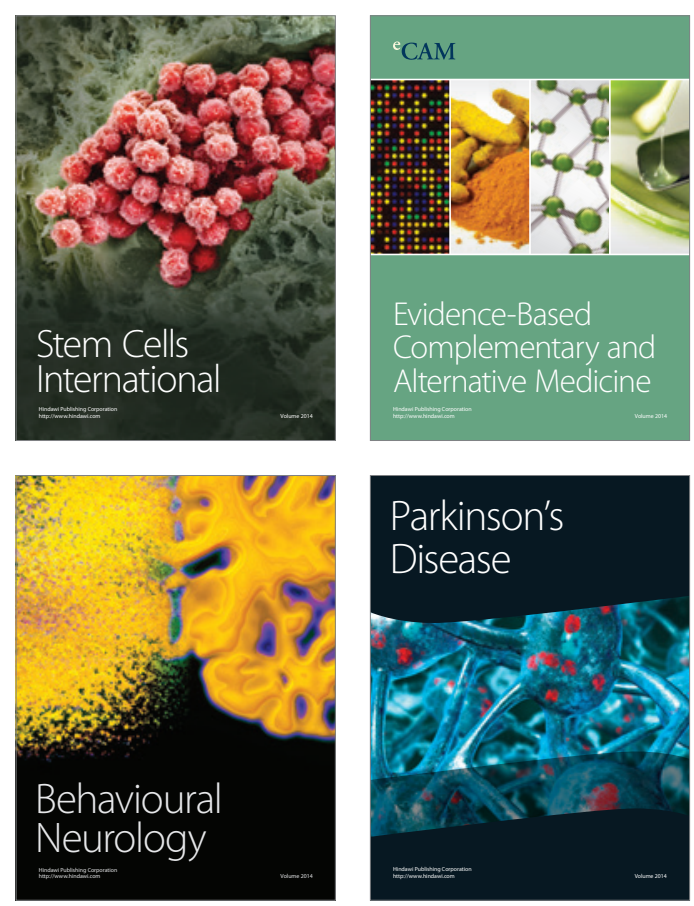

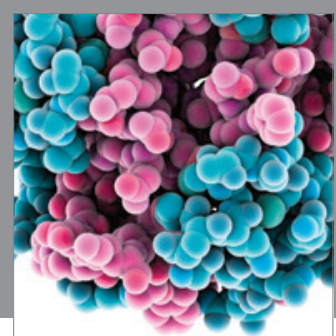

Journal of
Diabetes Research

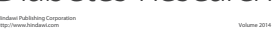

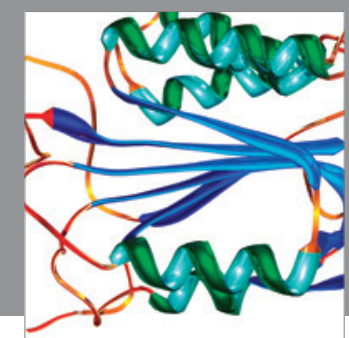

Disease Markers
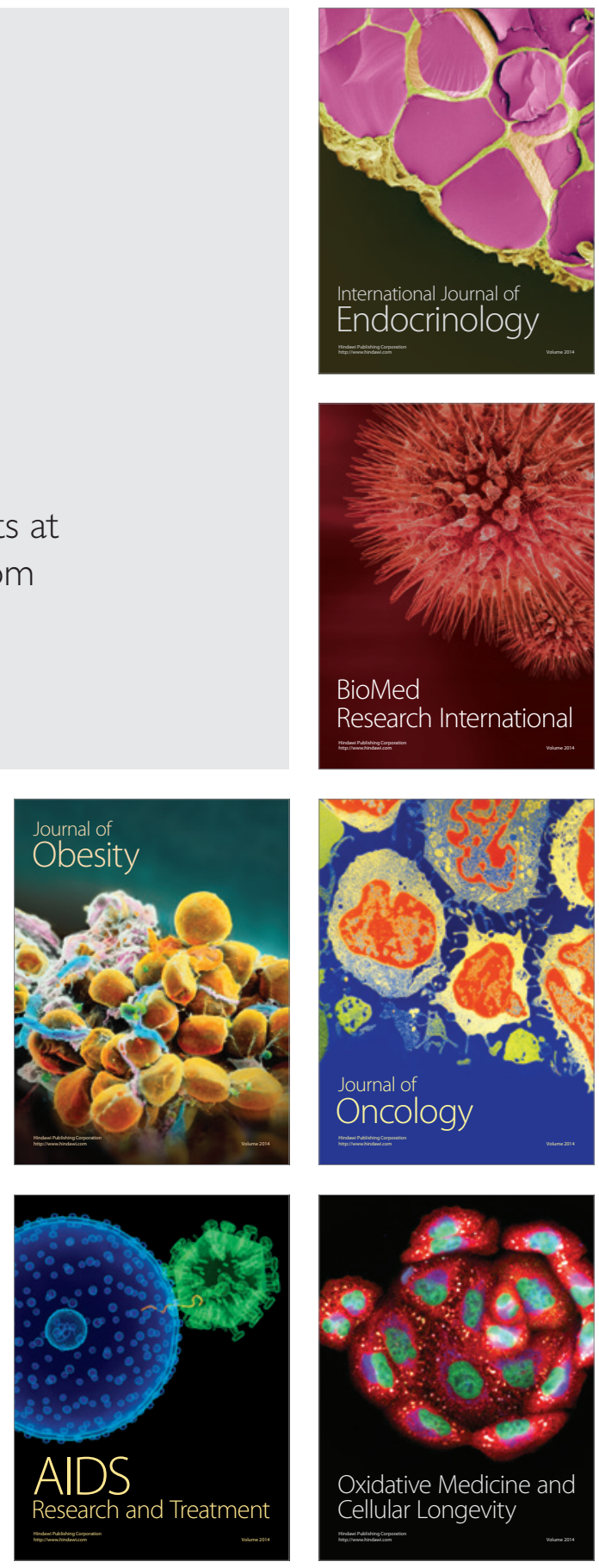